This item was submitted to Loughborough's Research Repository by the author.

Items in Figshare are protected by copyright, with all rights reserved, unless otherwise indicated.

\title{
Implementation of primary frequency regulation on fully rated wind turbine generators
}

\section{PLEASE CITE THE PUBLISHED VERSION}

https://doi.org/10.1109/CIEM.2017.8120815

\section{PUBLISHER}

(C) Institute of Electrical and Electronics Engineers (IEEE)

VERSION

AM (Accepted Manuscript)

LICENCE

CC BY-NC-ND 4.0

\section{REPOSITORY RECORD}

Bonfiglio, Andreas, Francisco M. Gonzalez-Longatt, Alessandro Labella, and Renato Procopio. 2019. "Implementation of Primary Frequency Regulation on Fully Rated Wind Turbine Generators". figshare. https://hdl.handle.net/2134/32383. 


\title{
Implementation of Primary Frequency Regulation on Fully Rated Wind Turbine Generators
}

\author{
Andrea Bonfiglio $^{1 *}$, Francisco M. Gonzalez-Longatt ${ }^{2}$, Senior Member, IEEE, Alessandro Labella ${ }^{1}$, Student Member, \\ IEEE, and Renato Procopio ${ }^{1}$, Member, IEEE \\ ${ }^{1}$ University of Genoa - DITEN Dept. of Electrical, Electronic, \\ Telecommunication Engineering and Naval Architecture \\ Via Opera Pia 11/A 16145 Genoa, Italy \\ 2 The Wolfson School: Electronic, Electrical and Systems \\ Engineering - Loughborough University \\ Loughborough, United Kingdom
}

*a.bonfiglio@unige.it

\begin{abstract}
The increased integration of wind generation via high power converters imposses numerous gauntlet to the management and control of modern power systems. One of them is caused by the decoupling effect between the power sources from the AC grid. It negatively impacts the system frequency response of modern power systems. This paper proposes a controller to enable the primary frequency regulation on fully rated wind turbine generators. The proposed controller is designed to enable primary frequency response mimiquing the classical syncrhonous generator controles. It includes a droop control and an other to enable the inertia response. Simulations on a test system are used to examine the frequency response provided by the prioposed strategy. The most important contributions of this paper is to demonstrate there is an actual limit value of the synthetic inertia gain that can be used in the controllers and that it is dependent on the system frequency noise.
\end{abstract}

Index Terms - frequency response, inertia control, power system, wind energy, wind turbine generator

\section{INTRODUCTION}

Traditional network power systems use synchronous machines as mainly generation units, infact they offer several advantages, in particular from the power system control point of view including the control of the system frequency [1]. Usually, the the wind power plants (WPPs) have been requested to contribute to power system frequency support throught their wind turbine generators (WTs). Nevertheless, as the inclusion of wind power generation into the classical power system is increasing, the modern grid code requirements have become more severe. As a consequence, the frequency support of the WTs rotating inertia during a system frequency disturbance (SFD) is evolving to a critical aspect of the modern grid codes. Several transmission system operators (TSOs) have discussed the inclusion of frequency response in grid code of many countries. The sensible balance between active power generation and consumption (and losses) is no more respected during an SFD event, thus, the system frequency must change to reach a new steady-state point (if it exists). The initial system frequency rate of chance during a SFD event is imposed by the total system inertia $\left(H_{\text {tnet }}\right)$ [2]. Modern power system are installing generation units with a technology that is not increasing the total system inertia. In fact, the total installed power capacity (MVA) of the power system is increasing but the effective system inertia remain the same as nowadays as a consequence the system frequency response and especially the inertia response is being negatively affected $[2,3]$. The reduced inertia has several negative effects, but for what concerns the frequency stability, there are more severe frequency excursions.

Recently, WT generator (WTG) has been enhanced with controllers that enable the system frequency support of power systems during a SFD. The controls act on WTG active power output accordingly to the system frequency. WTGs with frequency response controller allows an important improvement in the system performance during a distance and enhanced security. Numerous scientific publications present the main modelling [4,5] simulation [6] aspects of the inertial response controllers in the WTGs. Also, some publications provide an overview of the technical and economic impacts of massive penetration of WTs, considering their useful effects on transient under-frequency transients $[7,8]$.

This paper proposes a controller to enable the primary frequency regulation on fully rated wind turbine generators. The paper is built as follows: Section II presents a general basic outline of the ideas related to power system frequency response; Section III explain the proposed frequency controller to enable the primary frequency response on WTG. Section IV explain the main aspects of modelling for the used test and the WTG. Section V shows and discuss the time-domain simulations and results. A set of simulations are used to evaluate the good performance of the proposed primary frequency controller. One of the most important contributions of this paper is to demonstrate that exists a real limit value on the synthetic inertia gain used in the controllers, above which no stability is not guarantee and that it depends on the intensity of the disturbance event on the system frequency.

\section{POWER SYSTEM FREQUENCY RESPONSE}

The electrical frequency $f$ of the power system is indissolubly linked to the rotational velocity of the rotor of all synchronous machines directly connected to the grid, thus without any electronic device. Random changes in the electric 
power demand or power generation produces time dependant variations in the frequency, therefore, the system frequency is an electro-mechanical variable that must be constantly and precisely controlled using appropriate controllers to keep the instantaneous and continous power balance between the total demand and total generation. An active power change $(\Delta P)$, at any node of the network, is sensed throughout the whole electric power system as a change in the electric frequency $(\Delta f)$. Therefore, the system frequency is the most used marker to detect active power unbalanced between generations and loads.

For sake of completeness about frequency phenomena, one can consider an electric power system accounting for $N$ synchronous generators simultaneously working (for simplicity no synchronous motors are now considered). For a generic $i^{\text {-th }}$ synchronous machine, (1) defines the relation between the individual incremental unbalance power $\left(\Delta P_{i}\right)$ and the own electric frequency $\left(f_{i}\right)$ :

$$
\frac{2 H_{i}}{f_{0}} \frac{d f_{i}}{d t}=P_{m, i}-P_{e, i}=\Delta P_{i}
$$

in which $P_{m, i}$ is the p.u. mechanical power of prime mover, $\Delta P_{i}$ represents the generation/load unbalance in p.u.; $P_{e, i}$ is the p.u. electrical power; $H_{i}$ is the total inertia constant of the $i^{\text {-th }}$ machine (shaft, gears, turbine, evolving fluid etc.) expressed in $\mathrm{s} ; f_{i}$ is in $\mathrm{Hz}$ and $f_{0}$ is the rated frequency of the system in $\mathrm{Hz}$.

Summing the $N$ differential equations related to the individual generator, one can obtain the extended formulation of (1) related to the entire power system:

$$
\frac{2 H_{T}}{f_{0}} \frac{d f_{C O I}}{d t}=P_{m, T}-P_{e, T}=\Delta P_{T}
$$

where $P_{m, T}, P_{e, T}$, and $S_{T}$ are respectively the sum of the individual synchronous machine mechanical power, electric power and rating capacity $\left(S_{N, i}\right)$, instead the total system frequency inertia $\left(H_{T}\right)$ and the frequency of the center of inertia $\left(f_{C O I}\right)$ are defined as:

$$
\begin{gathered}
H_{T}=\frac{1}{S_{T}} \sum_{i=1}^{N} H_{i} S_{N, i} \\
f_{\text {COI }}=\frac{1}{\sum_{i=1}^{N} H_{i}} \sum_{i=1}^{N} H_{i} f_{i}
\end{gathered}
$$

Examining (2) and (3), it is easy to realize that the system frequency dynamic strongly depends on the total value of the system rotating inertia $\left(H_{T}\right)$. Therefore, the proliferation of renewables power plants that use high power electronic converters to connect to the grid, increases the total installed capacity $\left(S_{T}\right)$; however, the inertial response of that kind of generation untis is zero, it is because the power converter decouples the mechanical dynamic to the electric one of the generator. The enabling of the inertial response of power converter-based WTGs requires dedicated controllers.

\section{FREQUENCY CONTROLLER IN WIND TURBINE}

Even if generators interfaced to the grid through a power converters do not give a contribution to the Frequency Response (FR), this feature can be reach by an additional control to the converters [9]. The WT controller can act on the primary frequency control by two important parts of the FR [10]: (i) Inertial response using of the inertial controller and (ii) governor response, a slower response thought the adoption of the governor controller. The main value of this article lies on the study of the dynamic behaviour of the inertia controller on system FR. Several control approaches have been related in literature to implement the inertial controllers, all of them can be regroup in two main concepts: (i) Fast Power Reserve Emulation and (ii) Releasing "Hidden Inertia". This paper is focused only on the latter kind of control.

For the purpose to increase their capability, all the modern WTGs must use power electronic converters to operate at different speed, thus becoming variable speed WT (VSWT). Unfortunately, the WTGs based on back-to-back AC/DC/AC converters do not give spontaneous help to system frequency, in fact, it is well-known that the use of converters unbounds the rotational speed of the rotors from the system frequency [11]. Many controllers for modern WTGs have been created by the main WT producers, in order to emulate an inertial response, that is known with names such as Synthetic, Simulated, Emulated, or Artificial Inertial. Some of synthetic inertia controls on shelfs are: GE WindINERTIA ${ }^{\mathrm{TM}}$ [12], ENERCON ${ }^{\circledR}$ Inertia Emulation [13]. It is important to find out that the purpose of this kind of control is "to extract the stored inertial energy from the moving part on WTGs" [14].

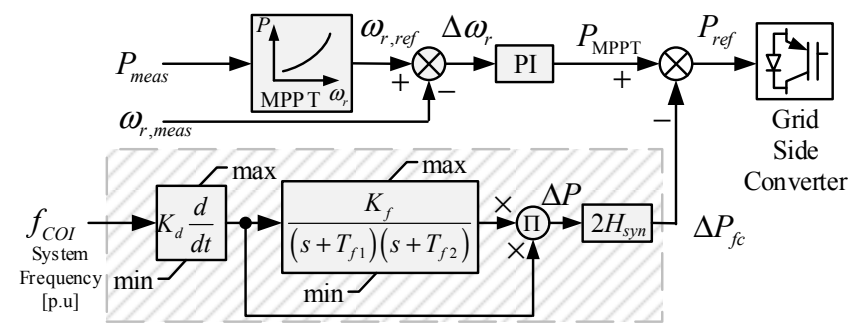

Figure 1. Common block diagram of MPPT controller with the graft of Synthetic inertia controller.

The synthetic inertia notion is based on a logic that allows to extract the kinetic energy from the WT rotating mass (rotor, gears etc.). This controller has been deeply investigated in literature [6], [15]. Such as control increases the electric power output of a WTG to shortly support grid frequency during strong downward frequency events. The active power of the frequency support controller, namely inertial power $\left(\Delta P_{f_{c}}\right)$, is reached by the following simple formula:

$$
\Delta P_{f c}=2 H_{s y n} f_{C O I} \frac{d f_{C O I}}{d t}
$$

where $\Delta P_{f c}$ is given in p.u., $H_{s y n}$ represents the synthetic inertia (s) and $f_{C O I}$ system frequency (p.u.). In Figure 1 is shown the use of a common synthetic inertia logic on a WT.

\section{Wind TURBINE GENERATOR MODEL}

The strategy presented in this paper is tested on a simplified configuration accounting the connection between the VSWT and the main grid as a totally inductive connection, composed by the line TL and the two transformers (T1 and T2), as suggested in Figure 2. 


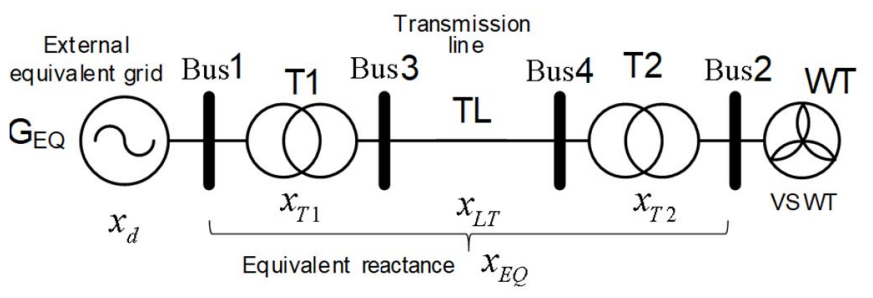

Figure 2. Overview of test system including an equivalent WTG.

For sake of simplicity, this is an active power lossless connection and the reactances of the step up and step down transformers and the reactance of the transmission line are in series, thus can be summed and one can use just the equivalent reactance $\left(x_{E Q}\right)$ which terminals are in bus 1 and 2. The total inertia $\left(H_{n e t}\right)$ of the main grid is $40.0 \mathrm{~s}$ (on VSWT machine power base) and its primary response is characterized by $5 \%$ equivalent droop. Figure 3 depicts a common architecture of a VSWT with direct-drive permanent magnet synchronous generator (PMSG). The proposed WT employs a full-rated power converter (FRPC) configuration. The structure modelled for this paper is characterized with the data available in [16-18], but escalated to represent an equivalent $3 \mathrm{MW}$ WT.

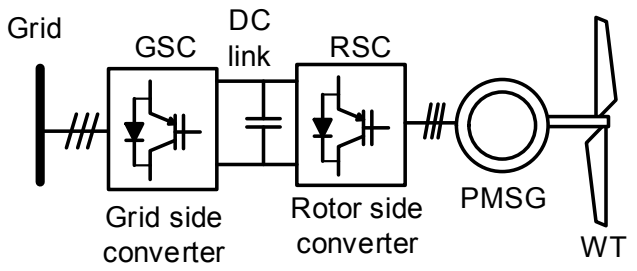

Figure 3. The generic configuration of a VSWT connected to a PMSG with a FRPC.

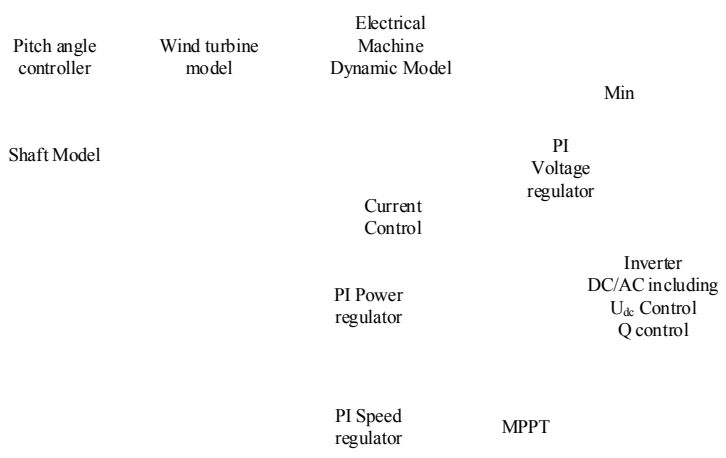

Figure 4. A representative block scheme depiected the main controlles of the VSWT with a FRPC.

Instead, Figure 4 displays a block scheme of the controller suited to a VSWT with a DD (direct drive) synchronous generator interfaced to the main grid by mean of a FRPC. For sake of simplicity in this article wind velocity is considered constant during all the simulations. VSWT rotor model is based on the well-known polynomic relation between wind speed and mechanical power [19], instead, a simple two mass model is used to represent shaft. The role of the pitch angle controller is to reduce the power extracted from the breeze when wind speed is over $25 \mathrm{~m} / \mathrm{s}$. Moreover, a MPPT controller is included in the scheme in order to guarantee the speed control of the WT. For what concerns the rotor side converter, there are two main control loops, namely: active speed/power loop and voltage loop. The stability of the two inner current is guarantee by these control loops. The GSC (grid side converter) is formed by two outer control loops, whose aim is to control (i) the voltage across the capacitor at the DC link and (ii) the reactive power supplied to main grid, by providing the reference signals for the two inner current control. The details of this control modelling are out of the scope of this paper, anyway, further details can be found on $[16,20]$.

\section{Simulations}

In this section a variety of simulations is presented using the network described in the previous section. Simulations are used as proof to find out, in different conditions, the contribution on the system frequency response given by the Releasing "Hidden Inertia", compared with what could happen using a standard FRPC WT without frequency support. The external grid is represented by an equivalent generator with a finite short circuit power, a droop and an equivalent inertia. Frequency disturbances are obtained by means of a load variation with respect to the steady state condition.

$$
P_{W T}+\Delta P_{f c}-\Delta P_{L}-P_{0, n e t}-K_{n e t}\left(\omega_{e}-1\right)=2 H_{n e t} \frac{d f}{d t}
$$

being: $P_{0, \text { net }}$ the load flow power, $K_{\text {net }}$ the network droop coefficient, $\Delta P_{L}$ is the active power load variation (before the contingency is equal to zero), $\omega_{e}$ is the network angular frequency, $P_{W T}$ is the power extract from the wind. WT controllers and power system model are implemented in Matlab $^{\circledR} /$ Simulink ${ }^{\mathrm{TM}}$ environment. In this paper, the SFD consists of an instantaneous increase (step) in active power demand $\left(\Delta P_{L}\right)$ at $t_{0}=10.0 \mathrm{~s}$. the simulation campaign was made for two/three different values of synthetic inertial $H_{\text {synt }}$. In the first part, $H_{s y n}$ is set to the $25 \%$ of the overall inertia of the WTG, thus $H_{s y n}=0.25 H_{W T G}$ and the system behaviour is assessed in three different conditions of power load step variation $\left(\Delta P_{L}=0.3,0.6\right.$ and finally 0.9 p.u. assuming the WTG rated power as power base). Figure 5 and Figure 6 reports the good behaviour of the proposed control with an initial rise of the system Rate of Change of Frequency (RoCoF) and a progressive reduction of the frequency support contribution as far as frequency tend to stabilize. The contribution of the proposed control increases with the amplitude of the load variation as the frequency derivative tend to increase in absolute value. The effect of the proposed control on the machine speed is provided in Figure 7 where it is possible noticing and initial slowdown of the rotor due to the loss of kinetic energy and a subsequent return to the MPPT speed. 


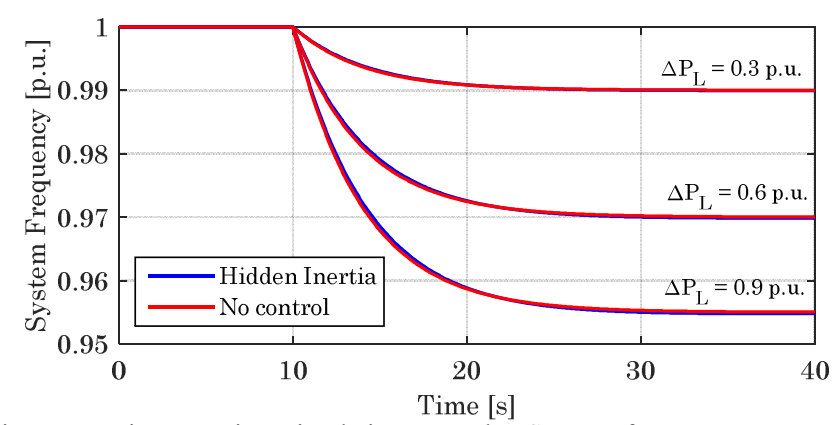

Figure 5. Time-Domian simulations resutls: System frequency response during SFD considering three different power imbalances $\left(\Delta P_{L}\right), H_{s y n}=$ $0.25 H_{W T G}$.

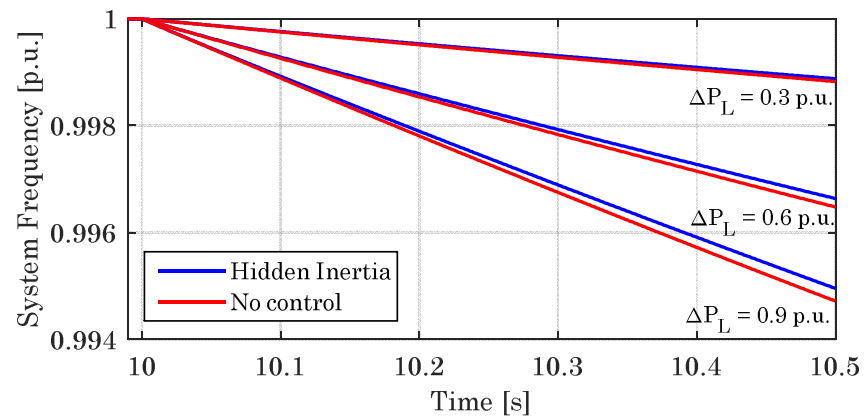

Figure 6. Details at the very beginning $(t=0.50 \mathrm{~s})$ of the system frequency response.

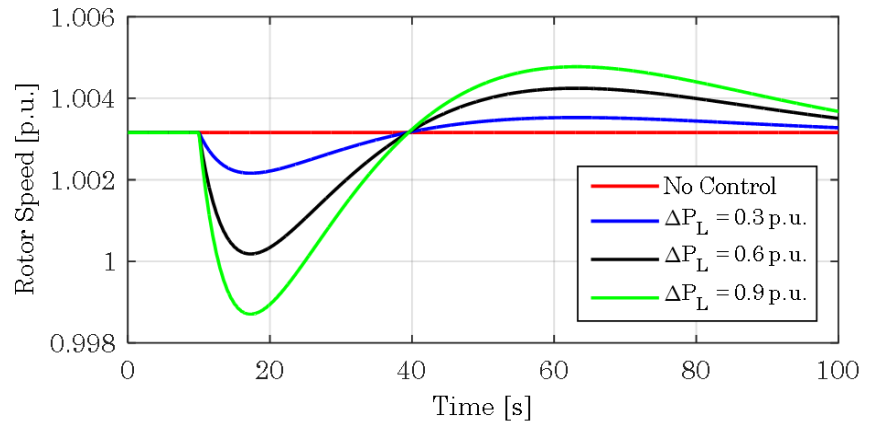

Figure 7. Time-Domian simulations resutls: Rotor speed response, the inertia controller gain is adjusted to be $H_{s y n}=28.0 \mathrm{~s}$.

Simulation highlighted that high values of the synthetic inertia $\left(H_{s y n}\right)$ may lead to dynamical electromechanical issues in the wind generator. As one can see from Figure 7 and Figure 8 instability arises for a value of the synthetic inertia equal to three time the wind generator rotor inertia and a load variation equal to $\Delta P_{L}=0.9$ p.u.. The effect of the instability may lead to the WTG stall, as shown in Figure 9 with the disconnection of the generator form the main grid and a consequent out of service. This effect could be very dangerous for the system since it may lead to a more sever frequency decreasing that could have a cascading effect.

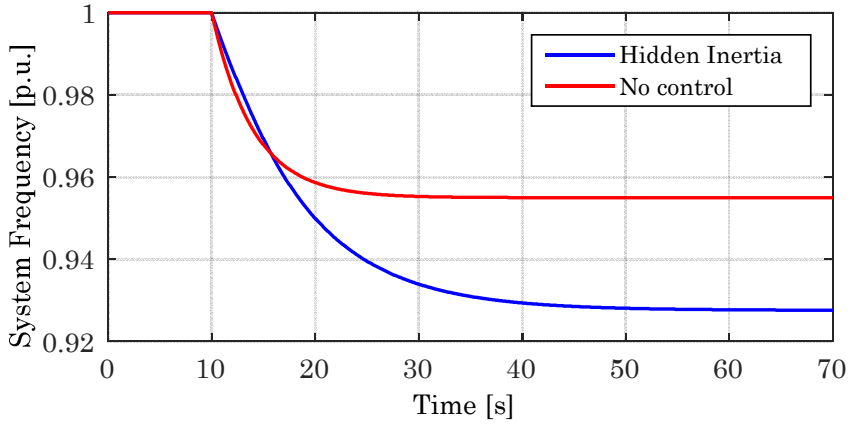

Figure 8. System frequency response: System frequency disturbance $\Delta P_{L}=$ 0.90 p.u. and inertia controller gain $H_{s y n}=3 H_{W T G}$.

The afore mentiones condition is extremelly critical from the frequency stability point of view, because it could create aanother SFD by the suddent disconnection of the WTG and decreasing in frequency to prohibitive limits. Looking to the mathematical equation describing the the synthetic inertia controller -equation (5), it should be notices the controlloes is not able to provide aditional active power contribution at the steady-state condition. As a consequence, it is simple to see tqhe frequency instability problem is not created by the by the inexistence of system equilibrium point but it might be created by the the interactions between the WTG controller and the synthetic inertia one.

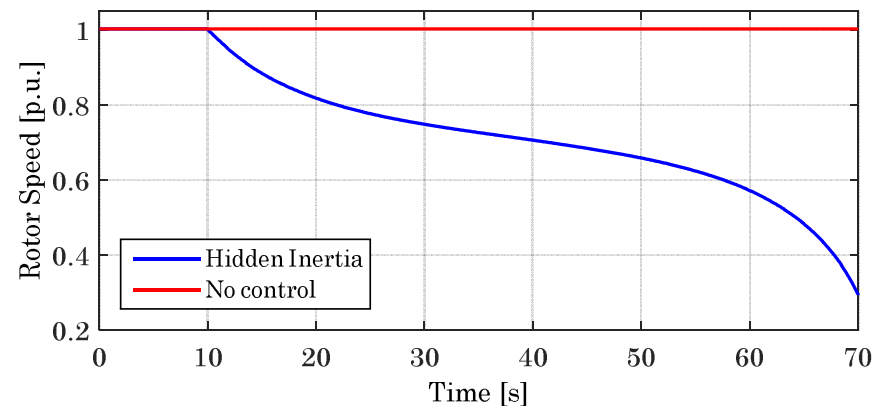

Figure 9. Time-Domian simulations resutls: Rotor speed response, SFD excited by $\Delta P_{L}=0.9$ p.u. and inertia controller gain is adjusted to be $H_{s y n}=$ $3 H_{W T G}$.

The variation of the limit value of the synthetic inertia for the proposed controller was tested by means of dedicated simulations for different values of the load variation. The synthetic inertia limit was defined for load variations equal to $0.30,0.60$ and 0.90 p.u. corresponding to a limit equal to 5,3 and 2 times the wind generator rotor inertia respectively. Analogous results can be achieved using a simplified grid model $[21,22]$ in which the effect of the transient on the grid inductance is neglected.

\section{CONCLUSION}

The present paper aimed at studying the possible contributions provided by renewable power plants, with specific focus on wind power generation, on the problem of frequency support. As discussed, the increasing number of generating unit characterized by stochastic generation and connected to the network thought power electronic devices is reducing the overall inertia of the system that is becoming more and more sensible to power variation and frequency dynamics. 
In this context wind power generators are one of the most promising source to provide frequency support because of the relevant quantity of kinetic energy stored in their rotating parts, otherwise not used. The main control strategy used to provide an inertial behaviour of under converter generators where briefly described in the first part of the paper namely hidden inertia, fast power reserve emulation and droop control. Then the focus was put on the hidden inertia controller that was fully described. The proposed controller was then integrated with the MPPT control logic of the WTG and implemented in MATLAB/Simulink in order to perform some dynamic simulation and validate the performances of the proposed structure. Simulation results pointed out the good impact of the hidden inertia controller on the support of the power system frequency accounting for different load variations and different values of the synthetic inertia parameter. Results also highlighted that high values of the synthetic inertia can lead the WTG to unstable behaviours resulting in a disconnection of the generator with potential cascading effects on the frequency of the system. The limit value of the synthetic inertia was found depending on the amplitude of the power variation occurring. The developing of the proposed work should focus on the better understanding of the unstable behaviour of the synthetic inertial controller finding suitable solution to improve the capability of the frequency support controller. Moreover, the proposed control will need to be integrated with the droop one in order to obtain a configuration that is closer to the behaviour of a tradition power plant in the contribution to frequency stability.

\section{REFERENCES}

[1] T. Ackermann, Wind power in power systems. Chichester: John Wiley \& Sons, 2005.

[2] F. Gonzalez-Longatt, "Impact of emulated inertia from wind power on under-frequency protection schemes of future power systems," Journal of Modern Power Systems and Clean Energy, pp. 1-8, 2015/08/12 2015.

[3] F. Gonzalez-Longatt, E. Chikuni, W. Stemmet, and K. Folly, "Effects of the synthetic inertia from wind power on the total system inertia after a frequency disturbance," in Power Engineering Society Conference and Exposition in Africa (PowerAfrica), 2012 IEEE, 2012, pp. 1-7.

[4] S. Yuan-zhang, Z. Zhao-sui, L. Guo-jie, and L. Jin, "Review on frequency control of power systems with wind power penetration," in Power System Technology (POWERCON), 2010 International Conference on, 2010, pp. $1-8$.

[5] A. Bonfiglio, F. Delfino, M. Invernizzi, R. Procopio, and P. Serra, "Criteria for the equivalent modeling of large photovoltaic power plants," in IEEE Power and Energy Society General Meeting, 2014.

[6] J. Ekanayake and N. Jenkins, "Comparison of the response of doubly fed and fixed-speed induction generator wind turbines to changes in network frequency," Energy Conversion, IEEE Transactions on, vol. 19, pp. 800$802,2004$.

[7] I. Erlich, W. Winter, and A. Dittrich, "Advanced grid requirements for the integration of wind turbines into the German transmission system," in Power Engineering Society General Meeting, 2006. IEEE, 2006, p. 7 pp.
[8] F. M. Gonzalez-Longatt, A. Bonfiglio, R. Procopio, and B. Verduci, "Evaluation of inertial response controllers for full-rated power converter wind turbine (Type 4)," in IEEE Power and Energy Society General Meeting, 2016.

[9] F. Gonzalez-Longatt, "Frequency Control and Inertial Response Schemes for the Future Power Networks," in Large Scale Renewable Power Generation, J. Hossain and A. Mahmud, Eds., ed: Springer Singapore, 2014, pp. 193-231.

[10]F. M. Gonzalez-Longatt, "Impact of emulated inertia from wind power on under-frequency protection schemes of future power systems," Journal of Modern Power Systems and Clean Energy, pp. 1-8, 2015/08/12 2015.

[11]G. Lalor, A. Mullane, and M. O'Malley, "Frequency control and wind turbine technologies," Power Systems, IEEE Transactions on, vol. 20, pp. 1905-1913, 2005.

[12]N. Miller, K. Clark, and R. Walling, "WindINERTIA: Controlled Inertial Response from GE Wind Turbine Generators," presented at the 45th Annual Minnesota Power Systems Conference, Minneapolis, Minnesota, 2009.

[13] S. Wachtel and A. Beekmann, "Contribution of Wind Energy Converters with Inertia Emulation to Frequency Control and Frequency Stability in Power Systems," presented at the 8th International Workshop on LargeScale Integration of Wind Power into Power Systems as well as on Transmission Networks for Offshore Wind Farms, Bremen, Germany, 2009.

[14]F. Gonzalez-Longatt and J. M. Roldan, "Effects of dc voltage control strategies of voltage response on multi-terminal HVDC following a disturbance," in Universities Power Engineering Conference (UPEC), 2012 47th International, 2012, pp. 1-6.

[15]J. Morren, S. W. H. de Haan, W. L. Kling, and J. A. Ferreira, "Wind turbines emulating inertia and supporting primary frequency control," Power Systems, IEEE Transactions on, vol. 21, pp. 433-434, 2006.

[16]A. Bonfiglio, F. Delfino, M. Invernizzi, and R. Procopio, "Modeling and Maximum Power Point Tracking Control of Wind Generating Units Equipped with Permanent Magnet Synchronous Generators in Presence of Losses," Energies, vol. 10, p. 102, 2017.

[17]A. Bonfiglio, F. Delfino, M. Invernizzi, A. Perfumo, and R. Procopio, "A feedback linearization scheme for the control of synchronous generators," Electric Power Components and Systems, vol. 40, pp. 1842-1869, 2012.

[18] A. Bonfiglio, F. Delfino, F. Gonzalez-Longatt, and R. Procopio, "Steadystate assessments of PMSGs in wind generating units," International Journal of Electrical Power \& Energy Systems, vol. 90, pp. 87-93, 9// 2017.

[19]J. G. Slootweg, "Representing distributed resources in power system dynamics simulations," in Power Engineering Society Summer Meeting, 2002 IEEE, 2002, pp. 176-178 vol.1.

[20] O. Anaya-Lara, Wind energy generation : modelling and control. Oxford: Wiley, 2009.

[21] A. Bonfiglio, M. Brignone, M. Invernizzi, A. Labella, D. Mestriner, and R. Procopio, "A Simplified Microgrid Model for the Validation of Islanded Control Logics," Energies, vol. 10, p. 1141, 2017.

[22]A. Labella, D. Mestriner, R. Procopio, and F. Delfino, "A simplified first harmonic model for the Savona Campus Smart Polygeneration Microgrid," in 2017 IEEE International Conference on Environment and Electrical Engineering and 2017 IEEE Industrial and Commercial Power Systems Europe (EEEIC / I\&CPS Europe), 2017, pp. 1-6. 